\title{
AVALIAÇÃO DOS EFEITOS DE DIFERENTES CONCENTRAÇÕES DE CLORO NA DESCAPSULAÇÃO E ECLOSÃO DE LARVAS DE ARTEMIA (Artemia sp.)
}

\section{EVALUATING THE EFFECTS OF DIFFERENT CONCENTRATIONS OF CHLORINE ON THE ARTEMIA LARVAE HATCHING AND SHEDING (Artemia sp.)}

\author{
A.G. DA ROCHA \\ C.S. KRAUSE ${ }^{2}$ \\ E.C. DE S. VIEIRA ${ }^{3}$ \\ F. DE FREITAS ${ }^{4}$ \\ L.C. CAIMI ${ }^{5}$ \\ R.R.V.P. FONSECA 6
}

\begin{abstract}
RESUMO
O presente trabalho foi realizado no Laboratório de Aqüicultura da Universidade Federal do Paraná (UFPR), com o objetivo de determinar a melhor dose de hipoclorito de sódio ( $\mathrm{NaClO}$ com $6 \%$ de ingrediente ativo) a ser empregada na descapsulação de oocistos de artemia. Os oocistos de artemia foram hidratados durante 1 hora, filtrados e submetidos aos tratamentos com cloro durante 10 minutos. As dosagens de cloro testadas foram as seguintes ( $\mathrm{NaClO}$ - hipoclorito de sódio $6 \%$ ): 0,38g, 0,75g, 1,50g, 3,00g e 6,00g de ingrediente ativo por litro de água. Depois da aplicação do cloro fez-se a lavagem dos oocistos para eliminar o cloro aplicado e logo após os oocistos foram colocados na água em frascos plásticos transparentes com aeração e luminosidade constante onde ficaram durante 53 horas. Para contagem dos náuplios foi pipetado um mililitro do frasco com aeração ligada. Para todas as repetições foram feitas três contagens e o parâmetro analisado foi o número de larvas eclodidas por mililitro da solução de eclosão. Os resultados foram submetidos a um teste de normalidade e foi verificado que os resultados de eclosão não tinham distribuição normal, portanto as médias não puderam ser usadas como termo de comparação entre os tratamentos. Então foram realizados testes não-paramétricos que usam a mediana como parâmetro de comparação entre os tratamentos. Tecnicamente observa-se a superioridade do tratamento de $1,50 \mathrm{~g}$ de cloro ativo que apresentou o ponto máximo de eclosão, tendo $50 \%$ dos dados de eclosão ao redor de 140 larvas eclodidas por mililitro.

Palavras-chave: artemia, oocistos, cloro, descapsulação.
\end{abstract}

\begin{abstract}
This paper was prepared in the Aquaculture Laboratory of the Federal University of the State of Parana, Brazil, with the purpose of determining the best sodium hypochloride ( $\mathrm{NaClO}$ with $6 \%$ active ingredient) dosage to be employed in the artemia oocysts hatching process. The artemia oocysts were hydrated for 1 hour, filtered and submitted to a 10-minute chlorine treatment. The chlorine dosages tested were the following ( $\mathrm{NaClO}-6 \%$ sodium hypochloride): $0.38 \mathrm{~g}, 0.75 \mathrm{~g}, 1.50 \mathrm{~g}, 3.00 \mathrm{~g}$ and $6.00 \mathrm{~g}$ of active ingredient per liter of water. Soon after chlorine application the oocysts were rinsed to eliminate the chlorine and immediately the oocysts were put into transparent plastic vials with water in the constant aeration and luminosity, where they remained for 53 hours. For the nauplii count one mililiter of the vial was put into a test tube with an interconnected aeration. Three counts were made for all repetitions and the threshold analysed was the number of hatched larvae per mililiter of hatching solution. The results were submitted to a normality test and it was determined that the hatching results did not show a normal pattern, therefore, it was not possible to use those averages as a comparison basis between treatments. Subsequently non-parametric tests were performed using the overall average as a comparison basis between treatments. Techically one can see the superiority of treatment with $1.50 \mathrm{~g}$ of active chlorine, which resulted in the highest hatching-out counts, with $50 \%$ of the observed data presented 140 larvae hatched per milimiter.
\end{abstract}

Key-words: artemia, cysts, chlorine, hatching.

${ }^{1}$ Aluno de Graduação do Curso de Zootecnia da Universidade Federal do Paraná - UFPR. Rua Visconde do Rio Branco, 1628, Centro, CEP 83055980, Caixa Postal 1026, São José dos Pinhais - PR - Brasil. Fone (41) 282 0980. E-mail: alexgomesr@hotmail.com;

${ }^{2}$ Aluno de Graduação Curso de Zootecnia - UFPR. sguikra@hotmail.com;

${ }^{3}$ Aluno de Graduação Curso de Zootecnia - UFPR. vieirae2004@ig.com.br;

${ }^{4}$ Aluna de Graduação Curso de Zootecnia - UFPR. freitas.fabiane@ig.com.br;

${ }^{5}$ Aluno de Graduação Curso de Zootecnia - UFPR. Iccaimi@hotmail.com;

${ }^{6}$ Aluno de Graduação Curso de Zootecnia - UFPR. riqui@uol.com.br. 


\section{INTRODUÇÃO}

A Artemia sp., conhecida também como camarão de salmoura, é um microcrustáceo, braquiópodo, pertencente ao filo Arthropoda e classe Anostracea, (STORER, 1991, citado por PEREIRA, 2001).

Possui quatro estágios de desenvolvimento (ovo, náuplio, metanáuplio e adulto) e alguns mecanismos de adaptação que permitiram que se tornassem cosmopolitas (LOPES et al., 2001). Euritermia, eurihaliania e possibilidade de viver em ambientes com baixa concentração de oxigênio dissolvido na água são alguns desses mecanismos (CÂMARA, 2002). Têm ainda formas alternativas de reprodução que facilitam a sua dispersão e perpetuação da espécie, tais como ovoviviparidade, partenogênese e encistamento (LOPES et al., 2001). Em condições normais, de baixa salinidade e elevada abundância de alimentos, os animais são ovovivíparos, isto é, as fêmeas incubam internamente os ovos e geram náuplios. Porém, se as condições ambientais forem demasiadamente estressantes, os animais adotam a reprodução ovípara, isto é, produzem e liberam oocistos de resistência.

O oocisto possui três camadas distintas, a mais externa é o córion, que protege o embrião contra impactos mecânicos e raios ultravioleta. A membrana cuticular está abaixo do córion, permite apenas a passagem de moléculas muito pequenas, e a cutícula embrionária é uma película muito fina e transparente, que separa o embrião das demais camadas, além de proteger o náuplio no momento de sua eclosão (LOPES et al., 2001).

As Artemias são ricas em proteínas, vitaminas (b-caroteno) e sais minerais, por isso são utilizadas em larga escala em cultivo de camarões e peixes na fase larval, acelerando o crescimento dos animais, recuperando os indivíduos doentes, deixando-os mais sadios (PEREIRA, 2001). Os náuplios são constituídos por cerca de $50 \%$ de proteínas, enquanto os adultos podem chegar a $60 \%$ (GOMES, 1986).

A qualidade nutricional associada às facilidades na utilização dos oocistos caracteriza a artemia como um alimento ideal a ser utilizado nas larviculturas comerciais (MARCHIORI, 1997).

A descapsulação é realizada para romper o córion que reveste o embrião. O córion é dissolvido através do uso de substâncias químicas, que além de eliminá-lo, fazem a assepsia da superfície dos oocistos, pois estes podem conter patógenos que ameaçando o ciclo produtivo podem reduzir a eficiência da larvicultura.

Os oocistos de artemia são um produto bastante caro e de grande importância na larvicultura de organismos aquáticos, por isso, é indispensável que se avalie criteriosamente a qualidade do produto que será utilizado. Alguns métodos utilizados para avaliar esta qualidade são: a eficiência de eclosão, o tempo que os náuplios levam para eclodir e a quantidade de náuplios gerados por grama de cistos (BARBIERI JUNIOR e OSTRENSKY, 2001).

Este trabalho foi realizado com o objetivo de determinar a melhor dose de hipoclorito de sódio ( $\mathrm{NaClO}$ com $6 \%$ de ingrediente ativo por litro, ou seja, $60 \mathrm{~g} /$ /itro) recomendada para ser empregada na descapsulação de oocistos de artemia, reduzindo assim as perdas durante este processo e otimizando a viabilidade técnica de obtenção de náuplios viáveis e melhorando os resultados econômicos.

\section{MATERIAL E MÉTODO}

O experimento foi realizado no mês de abril de 2003, no Laboratório de Aqüicultura, do Departamento de Zootecnia da Universidade Federal do Paraná (UFPR), em Curitiba.

O delineamento experimental adotado, em blocos totalmente casualizados, contou com cinco tratamentos que correspondem a 0,38 g, 0,75 g, 1,50 g, $3,00 \mathrm{~g}$ e $6,00 \mathrm{~g}$ de cloro ativo por litro de água, testados em triplicata, totalizando 15 unidades experimentais. Em cada repetição dos tratamentos foi usado um grama de oocistos desidratados.

Os oocistos de artemia foram hidratados em água doce durante 1 hora, com aeração constante, depois foram filtrados e submetidos aos tratamentos com cloro.

Os oocistos de cada repetição foram colocados em peneira de malha fina para conte-los, e as peneiras com os oocistos foram imersas parcialmente em frascos contendo um litro de água com o cloro diluído. Os oocistos de todas as repetições foram mantidos na água clorada por 10 minutos e logo após fez-se lavagem contínua dos oocistos em uma peneira fina, com água doce, até que não houvesse mais nenhum odor do cloro aplicado. Depois deste processo os oocistos foram colocados na água salgada para eclosão (35 gramas de sal para cada litro de água doce). A água com os oocistos foi mantida em frascos plásticos transparentes, com aeração e luminosidade constante onde os oocistos ficaram durante 53 horas. A ordem dos frascos para todas as repetições foi estabelecida por sorteio. Os frascos foram colocados em dois suportes de madeira, um com nove garrafas e outro com seis, os quais sustentavam também as duas lâmpadas fluorescentes de $40 \mathrm{~W}$ cada, conforme a Figura 1. 


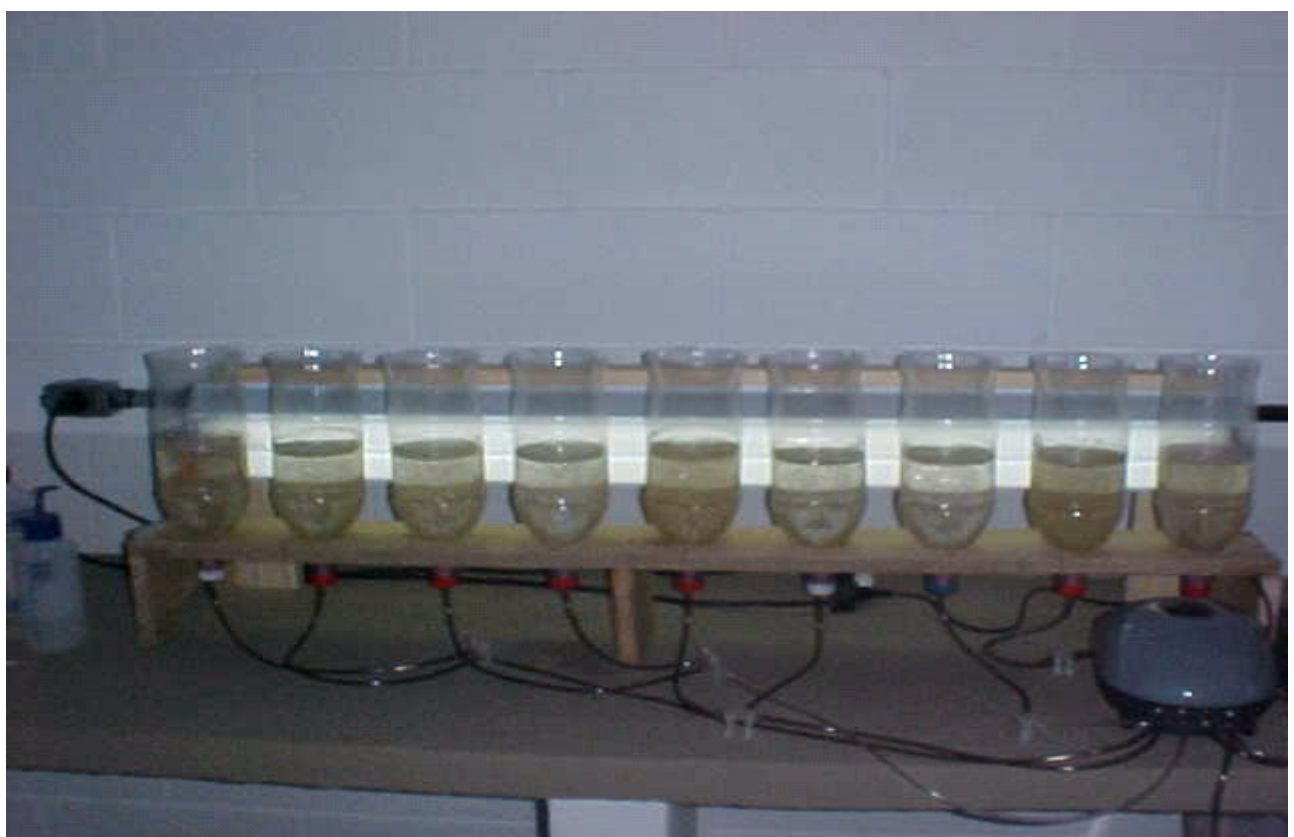

FIGURA 1 - Conjunto de nove garrafas para eclosão dos oocistos e duas lâmpadas fluorescentes em suporte de madeira. As mangueiras de silicone foram acopladas nas tampas das garrafas para aeração.

Cinqüenta e três horas depois que os oocistos foram colocados para eclodir, foi iniciada a contagem para avaliação do número de náuplios eclodidos em cada tratamento. O processo utilizado para contagem consistiu da pipetagem de um volume equivalente a um mililitro do conteúdo de cada frasco de incubação, e a posterior distribuição desse volume em pequenas gotas sobre placas de plástico translúcido, as quais foram colocadas sobre uma fonte de luz para melhor visualizar os náuplios que foram contados diretamente. Cada gota sobre o plástico continha de nenhum a cinco náuplios, portanto a contagem era facilitada. Para todas as repetições foram feitas três contagens.

Para efeito de padronização, na contagem do número de náuplios eclodidos em cada unidade amostral foram considerados somente os náuplios que estavam em movimento e que tivessem se livrado completamente do oocisto (Tabela 1).

O parâmetro analisado foi o número de larvas eclodidas por mililitro da solução de eclosão após 53 horas da colocação dos oocistos nos frascos. Este tempo tão alto, se considerado ao normal que é de 24 horas, deveu-se à temperatura ambiente dos dias do experimento. Observamos mínima de $2^{\circ} \mathrm{C}$ e máxima de $23^{\circ} \mathrm{C}$ durante os dias do experimento, mas as temperaturas dos frascos não foram mensuradas.

Os resultados obtidos foram submetidos a uma análise estatística através do software Statistica ${ }^{\mathrm{TM}}$ versão 6.0 .

$\mathrm{Na}$ análise estatística do experimento foi feito um teste de normalidade (Shapiro-Wilk) nos tratamentos. A partir deste teste foi verificado que os resultados de eclosão tinham distribuição normal, portanto as médias refletiam a distribuição dos dados obtidos e puderam ser usadas como termo de comparação entre os tratamentos.

Foi realizado também o teste de variância de Kruskal Wallis, que usa a mediana como parâmetro de comparação entre os tratamentos (Figura 2).

No passo seguinte foi realizado o Teste de Newman-Keuls (Tabela 2), que compara as médias e identifica a diferença entre os tratamentos por letras na mesma coluna.

\section{RESULTADOS E DISCUSSÃO}

Observa-se a superioridade do tratamento de $1,5 \mathrm{~g}$ de cloro ativo que apresentou o ponto máximo de eclosão, tendo $50 \%$ dos dados de eclosão ao redor de 140 larvas eclodidas por mililitro, enquanto que a variação para os tratamentos $0,38 \mathrm{~g}$ e $0,75 \mathrm{~g}$ foi entre 110 e 140 larvas eclodidas por mililitro, como pode ser verificado na Figura 2. 
ROCHA, A.G. et al. Avaliação dos efeitos de diferentes...

TABELA 1 - Número de náuplios eclodidos por mililitro de água. Três leituras por repetição.

Repetições

2

3

Leituras

\begin{tabular}{ccccccccccc}
\hline & $1^{\circ}$ & $2^{\circ}$ & $3^{\circ}$ & $1^{\circ}$ & $2^{\circ}$ & $3^{\circ}$ & $1^{\circ}$ & $2^{\circ}$ & $3^{\circ}$ \\
Tratamento & & & & & & & & & & \\
\hline $0,38 \mathrm{~g}$ & 112 & 112 & 88 & 130 & 122 & 143 & 145 & 142 & 127 \\
$0,75 \mathrm{~g}$ & 83 & 105 & 106 & 122 & 127 & 136 & 133 & 132 & 158 \\
$1,50 \mathrm{~g}$ & 141 & 132 & 147 & 138 & 133 & 139 & 166 & 140 & 152 \\
$3,00 \mathrm{~g}$ & 70 & 70 & 79 & 46 & 67 & 71 & 71 & 76 & 67 \\
$6,00 \mathrm{~g}$ & 43 & 35 & 27 & 67 & 95 & 87 & 48 & 67 & 52 \\
\hline
\end{tabular}

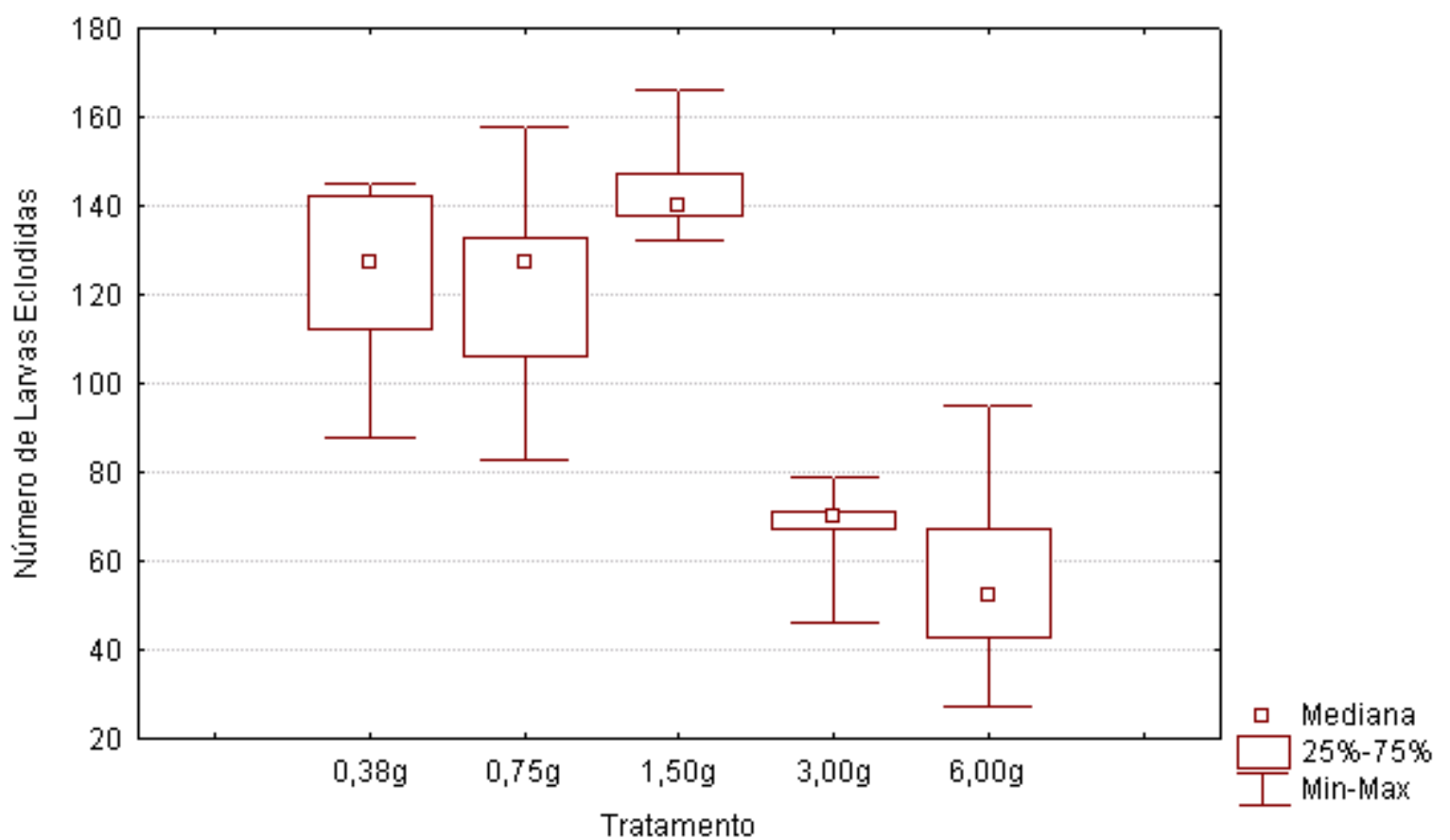

FIGURA 2 - Comparação entre as medianas dos cinco tratamentos, através do Teste de Kruskal-Wallis.

TABELA 2 - Comparação entre tratamentos dos dados de larvas eclodidas dos oocistos por mililitro da solução de eclosão pelo Teste Newman-Keuls. Letras distintas em uma mesma coluna representam diferença entre tratamentos $(p<0,05)$.

\begin{tabular}{cccccc}
\hline Tratamento & $\mathrm{N}^{0}$ Observações & Média & Mediana & Mínimo & Máximo \\
\hline $0,38 \mathrm{~g}$ & 9 & $124,56^{\mathrm{b}}$ & 127,00 & 88,00 & 145,00 \\
$0,75 \mathrm{~g}$ & 9 & $122,44^{\mathrm{b}}$ & 127,00 & 83,00 & 158,00 \\
$1,50 \mathrm{~g}$ & 9 & $143,11^{\mathrm{a}}$ & 140,00 & 132,00 & 166,00 \\
$3,00 \mathrm{~g}$ & 9 & $68,56^{\mathrm{c}}$ & 70,00 & 46,00 & 79,00 \\
$6,00 \mathrm{~g}$ & 9 & $57,89^{\mathrm{c}}$ & 52,00 & 27,00 & 95,00 \\
\hline
\end{tabular}


Tecnicamente, observa-se que houve diminuição das taxas de eclosão das larvas quando se aumentou a dose de cloro acima de $1,50 \mathrm{~g}$ de cloro ativo. O experimento mostrou que os melhores resultados entre os cinco tratamentos são com $1,50 \mathrm{~g}$ de cloro ativo, que corresponde a 25 mililitros de hipoclorito de sódio $6 \%$ por litro de água.

Comparando os resultados com as recomendações de outros autores verificamos grandes variações na dose de cloro recomendada.

Segundo Warland e Warland, em 2004, para descapsulação de dez gramas de oocistos de artemia é preciso adicionar hipoclorito de sódio com 12,5\% de ingrediente ativo (125 g/litro) com a concentração desejada de cloro ativo de $22 \mathrm{~g}$ por litro de água. Esta, portanto é uma concentração muito acima da ideal encontrada neste trabalho que é $1,50 \mathrm{~g}$ por litro de água, mas o fato se deve ao tempo de exposição dos oocistos ao ingrediente ativo, que segundo os autores é de 5 a 7 minutos, enquanto que para este trabalho o tempo foi de 10 minutos.

Já Teichert e Davis recomendam a adição $0,55 \mathrm{ml}$ de Clorox® $(5,25 \%$ de cloro ativo), ou seja, $0,03 \mathrm{~g}$ de cloro ativo para cada litro de água. O tempo recomendado pelo autor é de um minuto para descapsulação de 25 gramas de oocistos. O tempo e a concentração de cloro são menores que os aplicados em todos os tratamentos deste experimento.

Segundo Bloch 1998, é recomendável usar
$125 \mathrm{~g}$ de cloro disponível para descapsulação de oocistos. O tempo, segundo o autor, é determinado pela mudança de coloração dos oocistos durante a aplicação do cloro e a concentração de cloro é muito superior se comparada a qualquer tratamento deste experimento.

\section{CONCLUSÃO}

$\mathrm{Na}$ condição de tempo fixo em 10 minutos de exposição ao cloro a concentração de cloro ativo influenciou a eclosão das larvas de Artemia.

Os melhores resultados de eclosão foram obtidos com 1,5 g de cloro ativo para cada litro de água durante a descapsulação dos oocistos.

Espera-se que o resultado deste trabalho possa realmente ser utilizado por produtores e centros de pesquisa que trabalham ou necessitam das larvas de Artemia, para melhor utilização dos oocistos e redução dos custos.

\section{AGRADECIMENTOS}

Os autores agradecem ao Sr. Ubiratã Assis Silva pelo acompanhamento da execução do experimento e ao Professor Antonio Ostrensky Neto pela orientação científica.

\section{REFERÊNCIAS BIBLIOGRÁFICAS}

1. BLOCH, D. Decapsulated brine shrimp. Newsletter July 1998. Disponível em: http://members.iinet.net.au/ conquest/andy/ maswa/sept98.html\#story1, acesso em julho de 2004.

2. CAMARA, M. R. Artemia no Brasil do extrativismo ao cultivo. Departamento de Oceanografia e Limnologia - UFRN Universidade Federal do rio Grande do Norte.e-mail: mrcamara@ufrnet.br

3. ESTAÇÃO DE PISCICULTURA DE OLHÃO. Cadeia alimentar. Disponível: http://ipimar-iniap.ipimar.pt/crips/estacao_piscicultura/ artemia.html. Acesso em maio de 2003.

4. FATORES QUE INFLUENCIAM O CRESCIMENTO DAS MICROALGAS. Parte II Produção de náuplios de artemia. Disponível: http://www.sul-sc.com.br/afolha/monografia/camarao42.htm Acesso em maio de 2003.

5. GOMES, L.A.O. Cultivo de crustáceos e moluscos. São Paulo - SP, ed. Nobel, 1986, 226p.

6. JÚNIOR, R.C.B. \& NETO, A.O. Camarões marinhos (reprodução, maturação e larvicultura). Viçosa - MG, ed. Aprenda Fácil, 2001.

7. LOPES, W.B., et al. Desenvolvimento de um método alternativo ao uso de animais de laboratório para a avaliação da toxidade de extratos vegetais. Disponível: www.propp.ufu.br.html. Acesso em Abril 2003.

8. PEREIRA, G.L.S., Artemia sp. 2001. Disponível: www.artemia.hpg.ig.com.br. Acesso em maio de 2003.

9. SCHUMANN, K., Artemia, 2001. Disponível: www.fishgeeks.com. Acesso em maio de 2003.

10. TEICHERT, D. \& DAVIS, D. A. Production of saltwater shrimp in inland areas of alabama. Department of Fisheries and Allied Aquacultures - Auburn University - Alabama. Disponível em http://www.ag.auburn.edu/ ddavis/practical_info/fs_shrimpnurse.htm Acesso em julho de 2004.

11. WARLAND, T \& WARLAND, D. Artemia - descapsulation, hatching, feeding, on-growing and enrichment, South Australian Seahorse Marine Services. Disponível: http://www.ozreef.org/reference/artemia.html. Acesso em julho de 2004. 